\title{
A expressão escrita como tentativa de assimilação e representação de uma nova cultura nos romances Nove noites, de Bernardo Carvalho e $O$ enteado, de Juan José Saer
}

\author{
Kelly Viana dos Santos ${ }^{1}$ \\ Sylvia Helena Cyntrão ${ }^{2}$
}

\begin{abstract}
Resumo: A busca de elucidação sobre acontecimentos ligados ao choque cultural vivido por quem decidiu deixar seu ambiente familiar e se aventurar em nova cultura totalmente desconhecida, torna-se objeto de investigação nos romances Nove noites (2002), do brasileiro Bernardo Carvalho e O Enteado (1983), do argentino Juan Jose Saer. Seja por meio da investigação jornalística (Carvalho) ou por meio da restauração de dados da memória (Saer), a expressão escrita se destaca como elemento de arrefecimento do choque cultural vivido, bem como de articulação de uma forma mais adequada de assimilação e de representação de uma nova cultura. Em ambos os casos, o decorrer do tempo e a distância espacial entre os acontecimentos e aqueles que se dispõem a narrá-los se demonstra como fator complicador. Em Bernardo Carvalho, há reivindicação da expressão escrita como fonte de dados para a investigação dos acontecimentos e como auxílio à representação do personagem. Já no romance de Saer, a expressão escrita é ausente no momento dos acontecimentos, porém se faz necessária para completar a sua assimilação, no decorrer do tempo. Essas e outras questões serão analisadas mais detidamente neste estudo comparado, à luz dos conceitos de identidade narrativa e da tríplice mimese de Paul Ricoeur.
\end{abstract}

Palavras-chave: Choque Cultural. Identidade narrativa. Mimese. Bernardo Carvalho. Juan Jose Saer.

Os romances Nove Noites, do brasileiro Bernardo Carvalho, e O Enteado, do argentino Juan José Saer, trazem em comum, além da temática sobre o choque cultural vivido no encontro entre brancos e índios, a tentativa de assimilação e representação dessa experiência por meio da linguagem escrita. Vale destacar ainda que, segundo os autores, ambos os romances foram baseados em uma história real. Nove Noites teve origem a partir de um artigo de jornal - o jornal de resenhas da folha de São Paulo - que apenas menciona a lembrança do enigmático suicídio do etnólogo norte americano de 27 anos, Buell Quain, ocorrido no sertão brasileiro em 02 de agosto de 1939. Bernardo Carvalho se interessa pela história, pois passou

\footnotetext{
${ }^{1}$ Doutoranda em Literatura pelo Programa de Pós-Graduação em Literatura da Universidade de Brasília. Brasília, Brasil. E-mail: kvyanna@gmail.com (ii) https://orcid.org/0000-0003-3773-369X

${ }^{2}$ Doutora em Literatura pela Universidade de Brasília (2000). Professora Titular do Departamento de Teoria literária e Literaturas-TEL; pesquisadora no Programa de Pós-Graduação em Literatura-Póslit; líder do Grupo de pesquisa Poéticas contemporâneas-Vivoverso. Brasília, Brasil. E-mail: ssylvia.c@gmail.com iohttps://orcid.org/ 0000-0001-7738-6878
} 


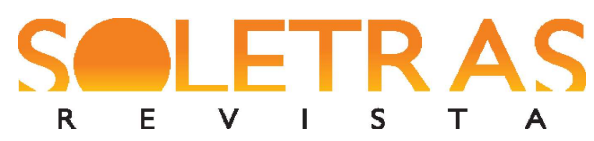

N. 38 - 2019.2 - KELLY VIANA DOS SANTOS

SYLVIA HELENA CYNTRÃO

parte da infância naquela região, e resolve ir à busca de mais informações sobre os motivos que levaram o jovem etnólogo ao suicídio. O resultado dessa investigação é a elaboração do romance que mistura acontecimentos históricos e ficção. $O$ Enteado, por sua vez, também teve inspiração em um fato histórico: o ataque à expedição de Juan Díaz de Solís na região do Rio da Prata no ano de 1515, por índios antropófagos, conforme relata o autor em entrevista (SCHWARTZ 2003). De acordo com o relato, Solís desembarcou com um pequeno grupo de marinheiros, sendo imediatamente atacados pelos índios, que os devoraram crus na frente dos outros marinheiros que estavam no barco e assistiram à cena.

Nos romances Nove Noites e O Enteado é possível perceber aquilo que Ricoeur (1997) chamou de entrecruzamento da História e da ficção, uma vez que se apropriam de uma narrativa histórica, a partir da qual compõem a intriga que norteará o romance. Aliás, o entrecruzamento da História e da ficção é inerente às narrativas, se considerarmos que uma toma emprestados elementos da outra para a composição da intriga. Ocorre que a narrativa histórica irá servir-se da imaginação a fim de reconstruir os fatos do passado, e a narrativa ficcional, do mesmo modo, vale-se das experiências vividas, históricas, para a constituição de suas intrigas.

$O$ Enteado relata a história de um órfão sobrevivente de uma expedição espanhola do século XVI que, durante dez anos, viveu numa tribo de índios antropófagos na região do Rio da Prata. O jovem órfão, que se intitula "o enteado", embarca como grumete numa expedição de busca por novas terras, mas acaba por assistir à morte, esquartejamento e ingestão de seus companheiros de expedição por índios da tribo Colastiné, habitantes daquela região.

O rapaz é poupado pelos índios, sem, no entanto, compreender os motivos. Então, vêse retido no meio deles pelos próximos dez anos em que convivem pacificamente, porém sem muitas intimidades. Durante todo esse tempo, ele passa a assistir, com a chegada de cada verão, a novas expedições serem atacadas e devoradas pelos índios em suas festas que terminavam em ingestão de grandes quantidades de bebidas inebriantes e em orgias incestuosas. Como ele, outros sobreviventes eram preservados pelos índios e tratados com reverência, sendo, no entanto, logo enviados de volta ao seu lugar de origem. Somente o enteado permanecia, sem conseguir compreender a razão disso, mas também sem saber exatamente para onde retornar. 


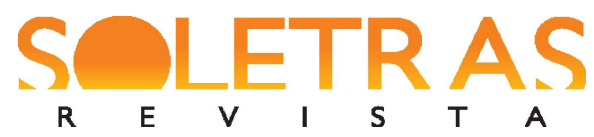

N. 38 - 2019.2 - KELLY VIANA DOS SANTOS

SYLVIA HELENA CYNTRÃO

Um dia, porém, chega o momento do enteado também ser enviado de volta. Ele é conduzido pelos próprios índios a se afastar da tribo numa canoa, mesmo sem saber para onde ir, pois perdera toda referência geográfica quando, dez anos antes, restara sobrevivente naquela região. Navegando sem rumo, é resgatado por um navio e retorna à sua cidade de origem, na Espanha. Ao se deparar novamente com a civilização espanhola, o enteado se dá conta do quanto se modificara, pois nem mesmo seu idioma materno conseguia falar e compreender direito desde que fora resgatado.

Apesar das dificuldades na comunicação, ainda no navio em que se encontrava resgatado, foi pressionado a relatar o que sabia sobre os índios Colastiné, inclusive se eles costumavam ingerir carne humana. As suas informações fragmentadas e confusas foram suficientes para que uma das embarcações chegasse até a tribo e dizimasse os índios num ataque surpresa. $\mathrm{O}$ enteado viu, de sua embarcação, os corpos sem vida dos índios e de muitos marinheiros que flutuavam na mesma direção do navio, até se dispersarem em mar aberto.

Ele começa a perceber, a partir de então, os efeitos que os anos de convivência com aqueles índios lhe causaram. Se, no início considerava-os selvagens, ao retornar à cidade e ter oportunidade de refletir e comparar as duas formas de convivência social, conclui que estivera enganado a respeito deles e, em sua memória, aqueles índios the pareciam mais civilizados em suas formas de conviver do que as outras pessoas com as quais mantivera relações na sociedade europeia.

Muitos anos depois, em idade avançada, decide escrever sobre os índios, numa tentativa de atualizar a existência daquela tribo que, embora não dispusesse de um sistema de escrita próprio para registrar a sua existência, consagrava anualmente a um estrangeiro essa responsabilidade. Tal foi a conclusão a que ele chegara, ao se lembrar de como se referiam a ele durante todo o tempo em que conviveram: def-ghi. Nunca conseguira compreender bem e se expressar no idioma dos Colastiné. As dificuldades se encontravam, principalmente, devido à pobreza da constituição daquele idioma em que uma palavra podia significar, ao mesmo tempo, muitas coisas similares, díspares ou contraditórias. Assim, quando começava a entender o significado de uma palavra, se deparava com ela numa significação completamente outra, o que tornava sua compreensão bastante confusa.

Def-ghi era o nome dado às pessoas que estavam ausentes; às visitas indiscretas que se demoravam; a um pássaro preto de plumagem amarela e verde que, domesticado, repetia 
alguns sons; a um objeto colocado no lugar de uma pessoa ausente para representá-la; ao reflexo das coisas na água; a quem se separava do grupo e se punha a gesticular imitando alguém; ao homem que ia à frente da expedição e retornava para relatar o que havia visto. Todos esses sentidos e tantos outros eram dados àquele termo, de modo que o def-ghi, fosse o que fosse, duplicava algo ou representava alguém. Refletindo sobre isso e por certas lembranças que lhe remetiam a situações semelhantes, compreendeu que sua vida fora poupada para que transformasse em narrativa a experiência de vida da tribo Colastiné.

Embora não dispusessem de linguagem escrita, os Colastiné possuíam diversas formas de representação, e o narrador descreve momentos em que crianças se envolviam em jogos miméticos de representação simbólica e de imitações. Também modelavam o barro, no qual projetavam seus sonhos, uma referência à arte abstrata produzida por eles. Mas o que eles esperavam mesmo do sobrevivente reverenciado por eles era que duplicasse, exteriorizasse e difundisse a imagem deles e do seu mundo por meio da escrita:

às vezes, algum índio se acercava, e, plantando-se em minha frente, embarcava num discurso interminável cheio de gestos lentos, explicativos, que se referiam ao horizonte, ao rio, às árvores, não sem que, por momentos, um braço dobrasse e a palma da mão batesse com energia o peito do orador, que assim se designava como o centro desse jorro de palavras curtas, rápidas e estridentes." (SAER, 2002, p. 84).

Devido a fatores como tempo cronológico, distância temporal e espacial dos acontecimentos, compreensão dos fatos e mesmo às limitações representativas da linguagem, nem toda experiência vivida, experimentada, pode ser reconfigurada por meio da narrativa e, quanto menos, pode ser esgotada pela linguagem. Entretanto, a fim de dar sentido às experiências humanas, lançam-se mão da linguagem como meio mais abrangente e apropriado de se atingir esse intuito.

O ato de narrar é, por assim dizer, o esforço em transportar ao nível da linguagem aquilo que se pode apreender da experiência vivida. Ao narrar, empreendemos mecanismos de articulação simbólica que nos proporcionam compreender melhor uma situação. Despojada de narração, a experiência vivida se cala, pois carece de articulação, e vai perdendo o sentido. 
Daí o significado da humanização do tempo, que destaca o ato de narrar como forma de clarear e articular a experiência humana, em relação à sua temporalidade, e assim, toda experiência humana que se desenvolve no tempo pode ser narrada. Conforme Ricoeur:

Desse entrecruzamento, dessa sobreposição recíproca, dessa troca de lugares, procede o que se convencionou chamar de tempo humano, em que se conjugam a representância do passado pela história e as variações imaginativas da ficção, sobre o pano de fundo das aporias da fenomenologia do tempo.(RICOEUR, 1997, 332).

Ao narrar uma experiência, mostramos que ela pode alcançar muito mais do que the impõem a sua temporalidade e finitude. Nas palavras de RICOEUR (1994, p.15), podemos dizer, então, que o "o tempo torna-se tempo humano na medida em que está articulado de modo narrativo; em compensação, a narrativa é significativa na medida em que esboça os traços da experiência temporal." Ou seja, a narrativa alcança sentido porque pode fazer a refiguração da temporalidade humana.

O enteado desembarcou na região do Rio da Prata aos quinze anos, órfão e carente de pertencimento. Esse sentimento de não pertencer se faz presente em todo o relato, mesmo nos dez anos em que vivera entre os índios. No entanto, quando em idade avançada resolve narrar a sua experiência na tribo Colastiné, é essa parte de sua vida que faz mais sentido: "Os índios, comigo, não se equivocaram; eu não tenho, exceto essa centelha confusa, nenhuma outra coisa para contar. Além disso, como lhes devo a vida, é justo que a pague voltando a reviver, todos os dias, a vida deles." (SAER, 2002, p. 165).

"Essa centelha confusa", à qual designa o período em que vivera entre os Colastiné, é justamente o que ele escolhe para ser transformado em tempo humano por meio da articulação narrativa. Não é coincidência que, em seu relato, considera os índios antropófagos mais humanos do que seus conviveres da civilização espanhola. E tudo o que sobrou da sua experiência vivida entre os Colastiné foi "essa centelha confusa", que, não obstante, ele consegue reacender por meio da narrativa. Á partir dela, o enteado recria o mundo dos Colastiné e, finalmente, alcança os sentidos que, durante tanto tempo, ficaram latentes em sua memória. 


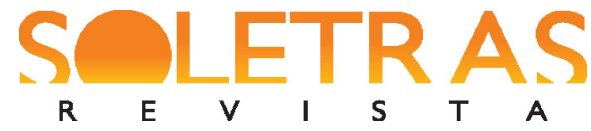

Ademais, cada ser comporta em si uma identidade narrativa, o que nos leva a compreender a importância da narrativa não apenas para a constituição do tempo humano, mas também para a constituição de si. Segundo RICOEUR (2006, p. 114): "sob a forma reflexiva do 'narrar-se', a identidade pessoal se projeta como identidade narrativa." Trata-se de um processo ininterrupto de construção de si mesmo a partir daquilo que dizem ao seu respeito, juntamente com o que você mesmo diz sobre si, e que se prolonga no tempo.

Por não possuírem um sistema de escrita, os Colastiné não puderam deixar registro escrito sobre si mesmos, o que prejudica a constituição de sua identidade narrativa. Essa responsabilidade designava ao sobrevivente de suas festas antropófagas anuais. Embora não seja possível, por meio do relato, fornecer uma visão fidedigna de suas vidas, a questão é: “dívida por dívida, qual delas, a do historiador ou a do romancista é a mais insolúvel?" (RICOEUR, 1997, p. 332). Dos Colastiné resta ao menos "essa centelha confusa," mas que mantém acesas as marcas daquelas vidas.

Diferentemente, Nove noites conta com alguns registros escritos, cartas e fotografias de seu personagem principal. Apesar da escassez desses dados, Buell Quain se expressa por meio da linguagem escrita e deixa a entrever uma série de questões que aguçam a curiosidade do autor Bernardo Carvalho. Quem era Buell Quain? A pergunta que intriga esse autor é justamente o que impulsiona a constituição de uma identidade narrativa. Carvalho recorre aos rastros deixados por Buell Quain, mas isso não é suficiente, então, acrescenta ao romance outras duas vozes narrativas: a de Manuel Perna, em sua suposta carta-testamento, e a sua própria voz, como investigador daquele suicídio.

A trama do romance Nove noites gira em torno desse acontecimento dramático: o suicídio do jovem etnólogo norte americano que viajara ao Brasil a fim de conhecer de perto uma tribo indígena do sertão brasileiro. Na viagem de regresso, o estudante comete suicídio na frente dos índios que o acompanhavam. Os motivos que o levaram a essa atitude extrema se tornam um mistério. $\mathrm{O}$ acontecimento trágico acaba ficando esquecido com o passar dos anos, até que um narrador enigmático decide investigar o caso, com a justificativa de que pretende compor com aquela história, um romance.

Enquanto no romance $O$ enteado, tudo o que há para o narrador reconstituir a história dos índios com os quais convivera é a memória, em Nove noites, a expressão escrita, registrada nas cartas do estudante, constituem aporte fundamental à investigação do narrador. 


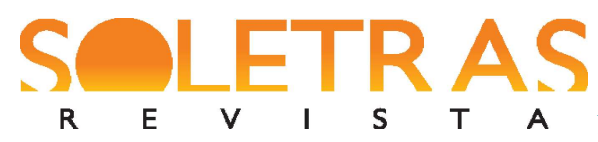

N. 38 - 2019.2 - KELLY VIANA DOS SANTOS

SYLVIA HELENA CYNTRÃO

Essas cartas se tornam de grande importância para a investigação e para a construção da intriga. Por meio delas o narrador busca a assimilação dos fatos, mas termina por completar a história com a sua própria imaginação. Além disso, há um documento escrito, um testamento, feito por Manuel Perna, no qual afirma possuir ainda uma carta secreta, cujo destinatário é aguardado por ele já há alguns anos.

Ao longo da narrativa, porém, descobre-se que a parte constituída por meio da imaginação do narrador é justamente aquele documento em torno do qual gira maior interesse. Encontramos aí um contraponto quanto ao uso da expressão escrita como fonte confiável para assimilação e representação de uma nova cultura: quanto de verdade pode haver em cada registro escrito? Quanto de imaginação? Nem a memória, nem o registro escrito podem ter total credibilidade. É necessário que, primeiramente, exista o desejo e o empenho em se investigar, resgatar, para, então, compor uma narrativa, ainda que ela represente apenas uma "centelha confusa" daquilo que realmente existiu.

Quanto ao personagem, o que se busca é uma resposta para a pergunta “quem sou eu?" O personagem é aquele a quem se imputa a ação e, portanto, está também configurado em intriga, ou seja, articula-se de forma narrativa. Ao responder as perguntas "quem", "o que”, "como" colocamos em desenvolvimento o encadeamento da intriga. Uma narração estabelece vínculos entre os acontecimentos e entre o personagem, pois ambos se desenvolvem em amálgama, ao passo em que vão sendo articulados de forma narrativa.

Em sua identidade, o personagem comporta elementos que são permanentes, e outros que vão se alterando conforme se engendra o enredo. Trata-se da identidade-ipse ou, nas palavras de RICOEUR (2006, p. 117) "quanto à identidade-ipse, pertence à ficção produzir uma série de variações imaginativas graças às quais as transformações do personagem tendem a tornar problemática a identificação do mesmo." As variações imaginativas, por seu caráter de multiplicidade, tornam a identidade pessoal confusa. Tal confusão pode levar a questão da identificação pessoal tão indecifrável até retroceder à pergunta nua: “Quem sou?”

Os romances Nove noites e $O$ enteado tratam justamente de se responder a essa questão crucial. Quem era Buel Quain? Quem eram os índios antropófagos que retiveram em sua tribo um jovem europeu? Imbuídos desse desejo de conhecer e de tornar conhecido, os autores se valem da linguagem escrita para, por meio dela, construir uma identidade narrativa 


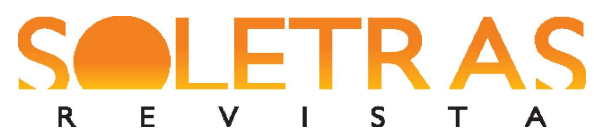

N. 38 - 2019.2 - KELLY VIANA DOS SANTOS SYLVIA HELENA CYNTRÃO

para esses personagens históricos dos quais se sabe tão pouco. Isso nos remete, finalmente, aos conceitos de tríplice mimese de RICOEUR (1997), a mimese I, mimese II e mimese III.

A mimese I corresponde ao tempo pré-figurado, pois se encontra no âmbito da experiência vivida. De fato, a história de Buell Quain aconteceu e existem registros a respeito. Alguns desses registros, como fotografias e cartas, Bernardo de Carvalho acrescentou ao livro. Em relação à narrativa de Saer, consta que a história de Francisco Del Porto, sobrevivente da expedição do espanhol Juan Diaz de Solís, também é verdadeira. Considerando-se que a mimese I toma por referência a experiência humana no nível dos acontecimentos reais, podemos afirmar que, nos romances ora analisados, esse aspecto está bastante claro e confirmado pelos autores.

A mimese II corresponde ao tempo configurado, encontra-se no âmbito da composição da narrativa. Trata-se, pois, das imagens, memórias e narrativas a respeito da vida, ou seja, dos registros da experiência humana no mundo. Não se trata da elaboração fidedigna da realidade por meio da narrativa, mas de sua figuração. Trata-se, outrossim, de mimese, conformação estrutural simbólica dos fatos ou de experiências humanas.

A mimese II surge da necessidade humana de dar sentido às suas vivências, de suscitar imagens evocativas dessas vivências e também do dever de memória para com aqueles que já não estão aí para se fazerem conhecer. Para isso faz-se necessário reunir e ordenar os eventos. Bernardo Carvalho e Juan Jose Saer, recorreram à imaginação para preencher as lacunas abertas pelo tempo, pela ausência de testemunhas vivas e pela memória. "O quase-passado da ficção passa assim a detector dos possíveis ocultos do passado efetivo. O que 'teria podido acontecer'" - o verossímil segundo Aristóteles - recobre ao mesmo tempo as potencialidades do passado "real” e os possíveis 'irreais’ da ficção. (RICOEUR, 1997, p. 331).

Entre a pré-figuração do tempo (mimese I) e a sua figuração pelos autores citados (mimese II), há um longo período de tempo cronológico. A história real de Francisco Del Porto, o órfão que inspirou Saer, aconteceu por volta do ano de 1515, e o romance $O$ Enteado foi escrito na segunda metade do século XX. Buell Quain morreu em 1939, e Bernardo Carvalho publicou Nove Noites no ano de 2002. O tempo vivido por esses personagens históricos, atualizado pela narrativa, se torna tempo humano e se expõe também aos percalços da mimese III. 


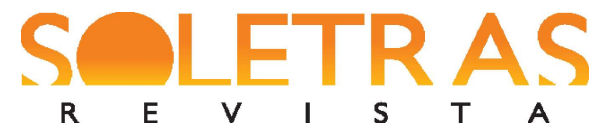

A mimese III corresponde ao tempo refigurado, encontra-se no âmbito da leitura e recepção das narrativas. A experiência vivida, uma vez figurada pela narração, é restituída à ação. Ela retorna ao mundo a partir de uma nova compreensão e também se expõe à novas interpretações. Essa dinâmica amplia e modifica a compreensão da ação. A mimese III é que nos permite agregar às nossas experiências as experiências de outros seres humanos, retirando do tempo a sua condição cronológica e elevando-o à condição de tempo humano em que passado, presente e futuro se fundem nas articulações que, por meio da narrativa, somos capazes de criar e recriar ad infinitum.

Nove noites estabelece e afirma vínculos com a realidade por diversos registros e informações. As fotografias, as cartas, personagens que existem ou existiram na realidade, espaços e fatos históricos, tudo isso se faz presente na narrativa. Entretanto, logo ocorre também a indefinição desses vínculos, quando se mesclam na intriga os registros reais com dados e informações fictícias. De repente, o leitor se encontra em meio a um campo minado pelos elementos da realidade e da ficção, sem saber ao certo onde pisa:

Isto é para quando você vier. É preciso estar preparado. Alguém terá que preveni-lo. Vai entrar numa terra em que a verdade e a mentira não têm mais os sentidos que o trouxeram até aqui [...] A verdade está perdida entre todas as contradições e os disparates. Quando vier à procura do que o passado enterrou, é preciso saber que estará às portas de uma terra em que a memória não pode ser exumada, pois o segredo, sendo o único bem que se leva para o túmulo, é também a única herança que se deixa aos que ficam, como você e eu, à espera de um sentido, nem que seja pela suposição do mistério, para acabar morrendo de curiosidade. Virá escorado em fatos que até então terão lhe parecido incontestáveis. Que o antropólogo americano Buell Quain, meu amigo, morreu na noite de 2 de agosto de 1939, aos vinte e sete anos. Que se matou sem explicações aparentes, num ato intempestivo e de uma violência assustadora. Que se maltratou, a despeito das súplicas dos dois índios que o acompanhavam na sua última jornada de volta da aldeia para Carolina e que fugiram apavorados diante do horror e do sangue. Que se cortou e se enforcou. Que deixou cartas impressionantes, mas que nada explicam. Que foi chamado de infeliz e tresloucado em relatos que eu mesmo tive a infelicidade de ajudar a redigir para evitar o inquérito. Passei anos à sua espera, seja você quem for,contando apenas com o que eu sabia e mais ninguém, mas já não posso contar com a sorte e deixar desaparecer comigo o que confiei à memória. (CARVALHO, 2002, p.7-8). 


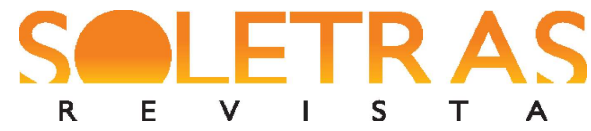

A carta-testamento de Manuel Perna se dirige a um destinatário desconhecido e, portanto, pode ser apropriada pelo próprio leitor. Ela busca prevenir seu destinatário sobre os melindres daqueles que buscam a realidade, e a encontram representada de forma narrativa. Com a expressão: "a memória não pode ser exumada", o narrador destaca a importância de se deixar algum registro da experiência vivida, embora nem a memória, nem esses registros possam ser considerados fiéis.

De qualquer forma, alguns de nós ficamos à espera de um sentido sobre a experiência vivida por nós mesmos ou por outras pessoas, pessoas até mesmo desconhecidas, das quais apenas ouvimos falar. Em algumas situações, nem a memória, nem os registros físicos e documentados são capazes de auxiliar na busca desse sentido. A linguagem escrita é, então, requisitada para compor e ordenar aquilo que, simbolicamente, encontra-se recalcado, sem achar meio de se expressar.

A morte de Buell Quain, da maneira abrupta e violenta como ocorreu, é um enigma que o narrador procura desvendar. Para isso, precisa recuperar a história e a identidade do etnólogo, pois a história daquele homem que viveu e morreu em um tempo cronológico determinado, ficou amortecida por mais de sessenta anos. Esse período se refere ao tempo pré-figurado (mímese I), em que os documentos, as lembranças, os registros sobre a vida e morte de Buell Quain, encontram-se fragmentados, dispersos, confusos. Nesse sentindo, suscita curiosidade, questionamentos e o sentimento de carência em relação às lacunas e segredos não revelados.

A linguagem escrita é requisitada, então, para tentar suprir esse sentimento de carência suscitado pela mímese I. A articulação da narrativa pode ser impulsionada como tentativa de assimilação e de representação da realidade por meio da linguagem escrita. Com a produção e publicação literária da obra Nove noites, a história de Buell Quain ingressa no tempo configurado (mímese II). A mímese II é mediadora entre a mimese I e a mimese III.

Da mesma forma, também é possível perceber nas obras Nove noites e O Enteado, o uso da linguagem escrita como tentativa de assimilação e representação de uma nova cultura. Mas a experiência vivida, enquanto se desenvolve no tempo cronológico, nem sempre é passível de se articular, simultaneamente, de forma narrativa. Buell Quain, em seus escritos, não se demonstrou capaz de alcançar o entendimento que buscava em relação a si mesmo e ao estranho, o outro, que eram os índios brasileiros e, muitas vezes, ele próprio. O enteado, por 


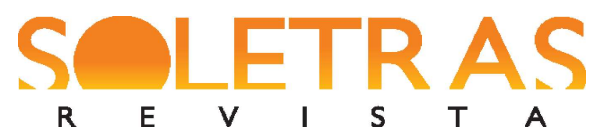

N. 38 - 2019.2 - KELLY VIANA DOS SANTOS

sua vez, somente muitos anos depois, ao dispor a sua experiência entre os Colastiné de forma narrativa, logra o êxito de exprimir uma "centelha confusa" daquela experiência.

Em sua tarefa de mediação entre a mimese I e a mimese III, a mimese II não pode se comprometer com a expressão fiel de uma realidade inequívoca. Muito pelo contrário, sua função é justamente buscar da realidade as referências e adequá-las aos recursos narrativos. Não fosse assim, não haveria tríplice mimese, uma vez que com a mimese II se encerrariam todas as reflexões e questionamentos. A mimese III existe porque a mimese II não ocorre de maneira circular, mas de forma a suscitar inúmeras e diferentes interpretações, reflexões e reconfigurações. A mimese III é, portanto, o tempo reconfigurado.

O desfecho de Nove noites nos diz muito em relação a isso, quando o narrador do tempo presente da narrativa revela que Manoel Perna não deixou nenhum testamento, e que ele imaginou a oitava carta. A carta redigida a um destinatário misterioso, aquela pela qual se esperava conhecer os verdadeiros motivos que levaram Buell Quain ao suicídio, nunca existiu.

O leitor se sente empurrado de volta ao início da narrativa, quando Manoel Perna, em sua suposta carta-testamento adverte: "Isto é para quando você vier. É preciso estar preparado. Alguém terá que preveni-lo. Vai entrar numa terra em que a verdade e a mentira não têm mais os sentidos que o trouxeram até aqui." Quando parecíamos caminhar para o desvendamento do mistério, tudo retorna ao campo das possibilidades e suposições, endossadas pelas interpretações de cada um. Ou seja, o caminho que percorremos da mimese I, pela via da mimese II, nos leva inexoravelmente à mimese III. Nas palavras do autor: "Cada um lê os poemas como pode e neles entende o que quer, aplica o sentido dos versos à sua própria experiência acumulada até o momento em que os lê.” (CARVALHO, 2002, p.114).

Apesar de todas essas implicações decorrentes do processo de transposição da mimese I à mimese III, a narrativa ocupa um lugar de destaque quando se trata de articular sentido à experiência vivida. Ao se deparar com uma cultura diferente, da qual não se tem domínio dos signos, símbolos e regras, é previsível a ocorrência de um choque cultural. No nível da experiência vivida, a mimese I vai sendo construída ao longo do tempo, na memória, nos gestos, na interiorização dos acontecimentos. Entretanto, é possível observar grande dificuldade em se realizar a figuração do tempo (mimese II) enquanto se vive o choque cultural. 
Buell Quain, por meio de suas cartas, faz uma tentativa de assimilação das culturas com as quais teve de conviver. Ele se deparou com diferentes culturas, seja a cultura brasileira de modo geral, em sua passagem pelo Rio de Janeiro, seja a cultura das diferentes tribos indígenas com as quais ele estabeleceu algum relacionamento. Em meio ao choque cultural em que se encontrava, a figuração do tempo, por meio da narrativa, não lhe ajudou a superar os seus próprios dilemas.

Alguns de seus relatos sobre como se sentia em relação à convivência com os índios, mostram a sensação de não pertencimento, a ocorrência patente do choque cultural: "Ele estava cansado de observar, mas nada podia lhe causar maior repulsa do que ter que viver como os índios, comer sua comida, participar da vida cotidiana e dos rituais, fingindo ser um deles.” (CARVALHO, 2002, p.55). Nesse caso, por meio da expressa escrita, Buell Quain esboça uma tentativa de assimilação e de representação daquela cultura à qual buscava se inserir. Contudo, isso não parecia ajudar, uma vez que ele ainda estava experimentando a préfiguração do tempo.

De outro modo, o enteado, que era analfabeto quando conviveu com os índios Colastiné, não dispunha da escrita para registrar sua experiência. Ele a vivenciou apenas como pré-figuração, guardando na memória aquilo que vivia ao longo do tempo. E, com o tempo e a agregação de novas experiências, ele finalmente pode transformar a sua experiência em narrativa.

O grumete de quinze anos, órfão e analfabeto necessitava de outras experiências de vida para dar conta daquele período completamente estranho, durante o qual esteve inserido como estrangeiro numa cultura marcada pela antropofagia. Ao retornar ao convívio com a sociedade espanhola, foi-lhe possível estabelecer comparações e até mesmo se questionar a respeito de qual sociedade era, na opinião dele, mais digna de ser chamada humana, se a dos índios antropófagos ou a europeia.

O choque cultural vivido pelo enteado foi, de certa forma, ampliado devido aos rituais de antropofagia e de relações sexuais incestuosas, ocorridos anualmente na tribo Colastiné. Esse tipo de comportamento era condenado veementemente pela sua sociedade de origem. Sendo assim, mesmo após ter convivido por dez anos com a tribo, o enteado jamais conseguiu assimilar aquela cultura, seja por esse fato ou por outros de menor grau de estranheza. 
Sua participação em uma trupe de teatro que fazia representações estereotipadas da tribo Colastiné lhe traz dinheiro para garantir sua sobrevivência na sociedade espanhola, mas também um grande sentimento de culpa por estar representando, de maneira tão equivocada e esdrúxula, a tribo que, a despeito dos rituais antropófagos, ele sabia não ser assim tão monstruosa como o teatro os apresentava. Então, em sua velhice, ele percebe que precisa narrar aquela experiência, cumprir a missão que lhe fora confiada pelos índios muitos anos antes.

O arrefecimento do choque cultural vivido por ele é alcançado por meio da narrativa. Ao dispor sobre o papel as palavras, ao articular de maneira narrativa a sua experiência vivida, o enteado começa a assimilar os sentidos daquela experiência. Ele verifica que a narrativa é capaz de dar aos índios uma forma mais adequada de representação, algo que até aquele momento, não havia sido construído.

O espaço temporal de mais de sessenta anos daquela experiência se demonstra como fator complicador para o relato, pois tudo o que ele tem são as evocações de sua memória. Também em Nove Noites a narrativa é construída após um espaço de mais de sessenta anos dos acontecimentos. Os dados disponíveis para a reconstituição das histórias de Buell Quain e dos índios Colastiné são escassos, muitas vezes dependentes exclusivamente de dados da memória e de relatos, mas quantas histórias semelhantes a humanidade viveu e nunca tiveram ao menos a chance de uma narrativa?

Ambos narradores dos romances procuram, por meio da narrativa, elucidar um acontecimento dramático, marcado pelo choque cultural. Tendo como suporte principal para a realização desse empreendimento os dados da memória, sabem que cometem erros. Entretanto, se arriscam e investem nessa tentativa de alcançar assimilação e representação de uma nova cultura por meio da expressão escrita. Apesar dos equívocos, podemos afirmar com Ricoeur que: "talvez haja crimes que não se devam esquecer, vítimas cujo sofrimento peça menos vingança do que narrativas". (RICOEUR, 1997, p. 327).

\section{Referências}

CARVALHO, Bernardo. Nove noites. São Paulo: Companhia das Letras, 2002. 


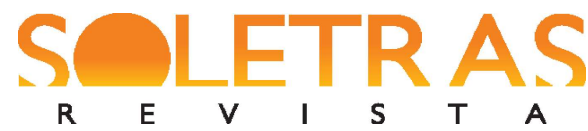

N. $38-2019.2$ - KELLY VIANA DOS SANTOS

SYLVIA HELENA CYNTRÃO

RICOEUR, Paul. O si-mesmo como outro. São Paulo: WMF Martins Fontes, 2014.

RICOEUR, Paul. Percurso do reconhecimento. Tradução Nicolás Nyimi Campanário. São Paulo: Edições Loyola, 2006.

RICOEUR, Paul. Tempo e narrativa (Tomo I1I). Campinas, SP: Papirus, 1997.

RICOEUR, Paul. Tempo e narrativa (Tomo 1).Campinas, SP: Papirus, 1994.

SAER, JuanJosé. O Enteado. São Paulo: Iluminuras, 2002.

SCHWARTZ, Jorge. Saer en la Universidad de San Pablo. Disponível em: http://www.avizora.com/publicaciones/literatura/textos/textos_2/0012_entrevista_saer.htm.

Acesso em: 01 de jul. de 2016.

\title{
The written expression as an attempt to assimilate and represent a new culture in the novels Nove noites, by Bernardo Carvalho and $O$ enteado, by Juan José Saer
}

\begin{abstract}
The search for elucidation of events connected with the cultural shock experienced by those who decided to leave their familiar surroundings and to venture into a completely unknown culture, becomes the object of investigation in the novels Nove Noites (2002), by the Brazilian Bernardo Carvalho and $O$ Enteado (1983), by the Argentine Juan Jose Saer. Whether through journalistic investigation (Carvalho) or through the memory data restoration (Saer), written expression stands out as a factor of cultural shock cooling and as a more appropriate way of assimilation and representation of a new culture, by the articulation of the narrative. In both novels, the passage of time and the spatial distance between events and those who are willing to narrate them is shown as a complicating factor. In Carvalho, the written expression is claimed as a data source for the investigation of the events and also as an aid to the representation of the character. In the novel of Saer, written expression is absent at the time of the events, but becomes necessary to complete its assimilation over time. These and other questions will be examined more closely in this comparative study, in the light of narrative identity concepts and triple mimesis of Paul Ricoeur.
\end{abstract}

Keywords: Culture Shock. Narrative identity. Mimesis. Bernardo Carvalho. Juan Jose Saer

Recebido em: 31 de maio de 2019.

Aceito em: 03 de setembro de 2019. 